\title{
Nintedanibo veiksmingumas ir saugumas, gydant idiopatinę plaučių fibrozę
}

\author{
EFFICACY AND SAFETY OF NINTEDANIB FOR THE TREATMENT OF IDIOPATHIC \\ PULMONARY FIBROSIS
}

LAIMA KONDRATAVIČIENĖ

LSMU MA Pulmonologijos klinika

\begin{abstract}
Santrauka. Idiopatinè plaučiu fibrozè (IPF) - tai lètinè, nežinomos kilmès, fibrozuojančios intersticinès pneumonijos specifine forma. IPF yra neišgydoma liga, tačiau dviem priešfibroziniais vaistais galime efektyviai sulètinti jos progresavima ir stabilizuoti pati procesa - tai pirfenidonas ir nintedanibas. Šioje apžvalgoje apibendrinami nintedanibo veiksmingumo ir saugumo duomenys iš klinikiniu tyrimu INPULSIS, TOMORROW ir INPULSIS-ON. Vertinant ju rezultatus, nintedanibas lètina ligos progresavima bei mažina ligos paūmèjimu dažnį. Nintedanibas yra gerai toleruojamas ir saugus vartoti. Dažniausiai pasireiškiantis nepageidaujamas reiškinys, susijęs su nintedanibo vartojimu, yra viduriavimas.

Reikšminiai žodžiai: idiopatine plaučiu fibrozè, nintedanibas, veiksmingumas, saugumas.

Summary. Idiopathic pulmonary fibrosis (IPF) is a fatal form of progressive fibrosing interstitial pneumonia with limited treatment options. This disease is not curable, but already there is a treatment that stabilizes the course of the disease and it seems to slow down the progression of the disease. These are two antifibrotic drugs: nintedanib and pirfenidone. In this article data from clinical studies INPULSIS, TOMORROW and INPULSIS-ON are reviewed. According to them, nintedanib slows down the progression of the disease at least up to 3 years and reduces the rate of exacerbations. Nintedanib is well-tolerated and safe to use. Diarrhea is the most frequent side effect, associated with the usage of nintedanib.
\end{abstract}

Key words: idiopathic pulmonary fibrosis, nintedanib, efficacy, safety.

\section{IVADAS}

Idiopatinė plaučių fibrozè (IPF) - tai specifinè lètinè liga, pasireiškianti progresuojančia plaučiu audinio fibroze, mažèjančiais plaučiu tūriais bei išsivystančiu kvẻpavimo nepakankamu. Ši liga dažniau pasireiškia suaugusiems vyrams ir pažeidžia tik plaučius. IPF etiologija neaiški, o prognozè bloga. Nors priežastinis ryšys nenustatytas, manoma, kad tam tikri rizikos veiksniai, pvz., rūkymas, gastroezofaginio refliukso liga (GERL), išoriniai aplinkos veiksniai, virusinès infekcijos gali turèti ịtakos ligos išsivystymui. Vidutinè išgyvenamumo trukmè siekia 2-5 metus po IPF nustatymo. Sergamumas šia liga yra nuo trijų iki devyniu atvejų per metus Europoje ir Šiaurès Amerikoje, kai paplitimas bendrojoje populiacijoje - nuo 2 iki 29 atvejų 100 tūkst. gyventojų. Pagrindiniai klinikiniai IPF požymiai: nuolatinis dusulys krūvio metu, sausas kosulys, auskultuojant abipus, daugiau apatinėse dalyse, išklausoma krepitacija (smulkus traškesys ịkvepiant) bei būgno lazdelès formos pirštai. Nors liga neišgydoma, tačiau daug vilčių teikia priešfibroziniai vaistai, kurių tikslas - stablizuoti ligos eigą arba bent sulètinti jos progresavimą. Vienas iš jų - tai nintedanibas. Šis vaistas buvo patvirtintas JAV Maisto ir vaistų administracijos (angl. USA Food and Drug Administration, FDA)
2014 m. spalio mèn., o Europos vaistų agentūros (angl. European Medicines Agency) - 2015 m. sausio mèn.

\section{KLINIKINIAI TYRIMAI TOMORROW IR INPULSIS}

Nintedanibas yra tirozino kinazès inhibitorius, kuris slopina daugelị signalinių receptorių, dalyvaujančių IPF patogenezèje, pvz., fibroblastų, kraujagyslių entodelio, trombocitų kilmès augimo veiksnio. TOMORROW - tai pirmasis klinikinis tyrimas, ịvertinęs IPF gydymo nintedanibu veiksmingumą. Tai daugiatautis, dvigubai aklas, atsitiktinių imčių, placebu kontroliuojamas, 52 savaičiu, II fazès klinikinis tyrimas. Šiame tyrime pacientai buvo suskirstyti i penkias grupes: placebo grupé, grupé, kurioje nintedanibas buvo vartotas po $50 \mathrm{mg}$ vieną kartą per parą ir grupés, kuriose nintedanibas vartotas po 50, 100 ir $150 \mathrm{mg}$ du kartus per parą. IPF gydymas, skiriant nintedanibą po $150 \mathrm{mg}$ du kartus per parą, parodè ryškų forsuotos gyvybinès plaučių talpos (angl. Forced Vital Capacity, FVC) kritimo mažejimą: apytiksliai - 68 proc. nuo 190 $\mathrm{ml}$ per metus placebo grupeje ( 95 proc. pasikliautinasis intervalas (PI) $0,26-0,12$ ) ir $6 \mathrm{ml}$ nintedanibo grupeje (95 proc. PI 0,14-0,03; $\mathrm{p}=0,06$ ). Reikšmingas skirtumas tiriamųjų grupėse rodo, kad nintedanibas lètina IPF progresavimą. Pacientams, kuriems buvo skirtas 


\section{Farmakoterapija}

nintedanibas, nustatyti retesni ligos paūmèjimai ir geresnè su sveikata susijusi gyvenimo kokybė. Šio tyrimo rezultatai padarè įžangą INPULSIS-1 ir INPULSIS-2 klinikinių tyrimų modeliui - tai du pakartotiniai, dvigubai akli, atsitiktinių imčių, placebu kontroliuojami, 52 savaičių trukmès, III fazès klinikiniai tyrimai. Šiuose tyrimuose dalyvavo 1061 pacientas iš 24 šalių. Kaip ir TOMORROW tyrime, nintedanibas reikšmingai sumažino metinị FVC kritimą (abiejų tyrimų rezultatai skirtumas tarp grupių 109,9 ml per metus; 95 proc. PI 75,9-144,0; $\mathrm{p}<0,001$ ) (1 pav.).

\section{ILGALAIKIS NINTEDANIBO POVEIKIS - INPULSIS-ON KLINIKINIS TYRIMAS}

Ilgalaikis nintedanibo poveikis buvo aprašytas atvirame tęstiniame klinikiniame tyrime INPULSIS-ON, kuriame dalyvavo ir pacientai iš INPULSIS tyrimų, tęsiantys nintedanibo vartojimą. Iš viso 734 pacientai (91 proc. dalyvavusių INPULSIS tyrimuose) buvo įtraukti į INPULSIS-ON tyrimą (430 pacientų nintedanibo vartojimą pratęsè, o 304 - pradejjo jị vartoti pirmą kartą). Tyrimas truko ir duomenys rinkti 144 savaites. Vidutinis nintedanibo vartojimo laikas pacientų, kurie pirmą kartą pradejo jị vartoti INPULSIS-ON tyrime, buvo 28,8 mèn. Šių pacientų FVC mažèjimas per 144 savaičių laikotarpi buvo panašus ì pacientų, dalyvavusių INPULSIS tyrime (grupeje, kurioje pacientai tęsè nintedanibo vartojimą - FVC sumažèjo 142,6 ml, o grupeje, kurio nintedanibas buvo pradètas vartoti pirmą kartą - 112,4 ml; INPULSIS tyrime FVC sumažèjo 113,6 ml nintedanibo grupeje, o placebo - 223,5 $\mathrm{ml}$ per metus). Vidutinis nintedanibo vartojimo laikas INPULSIS ir INPULSIS-ON tyrimuose buvo 40,7 mèn., kai ilgiausiai vaistas buvo vartotas 63,1 mèn. Šie tyrimai rodo, kad nintedanibas efektyviai mažina FVC kritimą bent trejus metus.

Nintedanibo veiksmingumas įrodytas ir klinikineje praktikoje. Prieš nintedanibo patvirtinimą Vokietijoje, pacientai, kuriems netiko gydymas pirfenidonu, buvo ittraukti į nintedanibo skyrimo programą. Lyginant su INPULSIS tyrimo dalyviais, šios programos dalyviai buvo vyresni (duomenys pateikiami kaip amžiaus vidurkis \pm standartiné paklaida (SP)): $71 \pm 8$ metai lyginant su $67 \pm 8$ metai; jų pradinis FVC buvo mažesnis (FVC vidurkis proc. nuo būtinojo dydžio \pm SP): $64 \pm 17$ proc. ir $79,6 \pm 17,8$ proc., o IPF diagnozè nustatyta ilgesnị laiką (metai po diagnozès \pm SP): 5,8 $\pm 2,4$ metu

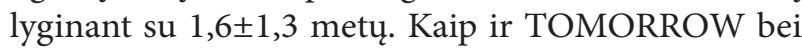
INPULSIS tyrimuose, nintedanibas daugumai pacientų sulètino ligos progresavimą. Po 6 mẻn. gydymo nintedanibu 63 proc. pacientų $(n=30$ iš 48$)$, FVC kritimas sumažèjo 5 proc. nuo pradinio ir, manoma, stabilizavo ligą. Šios studijos autoriai pastebejo, kad gydymas nintedanibu stabilizavo ligos progresavimą 62 proc. pacientams ( $\mathrm{n}=13$ iš 21 ), kuriems nebuvo atsako ì gydymą pirfenidonu per paskutinius 6 mèn.
Šiems pacientams iki gydymo nintedanibu FVC vidutiniškai sumažėjo $17,3 \pm 6$ proc., po 6 mèn. gydymo nintedanibu FVC vidutiniškai pakito $2 \pm 1,8$ proc. Likusiems pacientams ( $\mathrm{n}=8$ iš 21 ), IPF progresavo (FVC sumažèjo $15,7 \pm 4$ proc. prieš pradedant vartoti nintedanibą, lyginant su $18 \pm 11$ proc. sumažejimu po gydymo). Nors reikalingi išsamesni tęstiniai tyrimai, šie rezultatai rodo, kad nintedanibas gali būti veiksmingas pacientams, kuriems netinka gydymas pirdenidonu arba nèra gydymo atsako it ji.

\section{NINTEDANIBAS MAŽINA IPF PAŪMĖJIMŲ DAŽN}

TOMORROW ir INPULSIS tyrimuose nagrineti ir IPF paūmèjimai, apibrěžiami kaip 1 mèn. laikotarpiu atsiradęs ūminis, kliniškai reikšmingas kvèpavimo pablogejjimas, kurio negalima paaiškinti kitomis žinomomis ligomis, pvz., pneumonija, plaučių embolija, pneumotoraksu arba širdies nepakankamumu. Paūmejjimai yra susiję su padidèjusia mirties rizika, todèl laikotarpis iki pirmo ligos paūmejjimo yra kliniškai reikšmingas rodiklis. TOMORROW ir INPULSIS klinikiniai tyrimai pateikè ịvairius nintedanibo rezultatus paūmèjimų metu. INPULSIS-1 klinikiniame tyrime, pacientai nintedanibo ir placebo grupèse pirmo paūmèjimo metu nesiskyrè (rizikos santykis (RS) 1,15 ; 95 proc. PI 0,54-2,42; $\mathrm{p}=0,67$ ). INPULSIS-2 tyrime - priešingai: nintedanibas reikšmingai prailgino laikotarpị iki pirmo paūmèjimo (RS 0,38 ; 95 proc. PI 0,19 - 0,77; $\mathrm{p}=0,005)$ ir sumažino paūmèjimo dažni TOMORROW tyrime lyginant su placebo grupe (TOMORROW tyrime 2,4 atvejo, placebo grupeje 15,7 atvejo 100 pacientų per metus, $\mathrm{p}=0,02$ ).

Jungtinio TOMORROW ir INPULSIS tyrimo metu lyginti pacientų, vartojusių nintedanibą po $150 \mathrm{mg}$ per dieną, duomenys. Trijų tyrimų duomenys parodè, kad nintedanibo grupejje mažiau pacientų patyrè ligos paūmejjimą per 52 savaičių laikotarpi ( 4,6 proc.), lyginant su pacientais placebo grupeje ( 8,7 proc.). Gydymas nintedanibu 47 proc. sumažino pirmo dokumentuoto IPF paūmèjimo riziką (RS 0,53 proc.; 95 proc. PI $0,34-0,83 ; p=0,0047)$. Ligos paūmèjimas fiksuotas kaip sunkus nepageidaujamas reiškinys 3,6 proc. pacientų nintedanibo grupeje, 6,1 proc. - placebo grupeje.

INPULSIS-ON tyrimo duomenys kaip TOMORROW bei INPULSIS tyrimų rezultatai, parodè, kad nintedanibas yra veiksmingas mažinant paūmèjimų dažnị mažiausiai trejus metus. Paūmèjimų dažnis INPULSISON tyrime per 144 savaites (5,3 atvejų tęsiantiems nintedanibo vartojimą ir 5,2 atvejo pirmą kartą ji pradejus vartoti 100 pacientų per metus) buvo panašus kaip ir INPULSIS tyrimuose (5,2 atvejo 100 pacientų per metus) ir mažesnis nei paūmèjimų dažnis placebo grupeje (8 atvejai 100 pacientų per metus).

TOMORROW ir INPULSIS tyrimų analizė parode், kad nintedanibas 43 proc. sumažina mirštamumą gydymo metu (nintedanibo grupejje mirè 3,5 proc., placebo grupèje - 6,7 proc. pacientų; RS 0,57; 95 proc. 


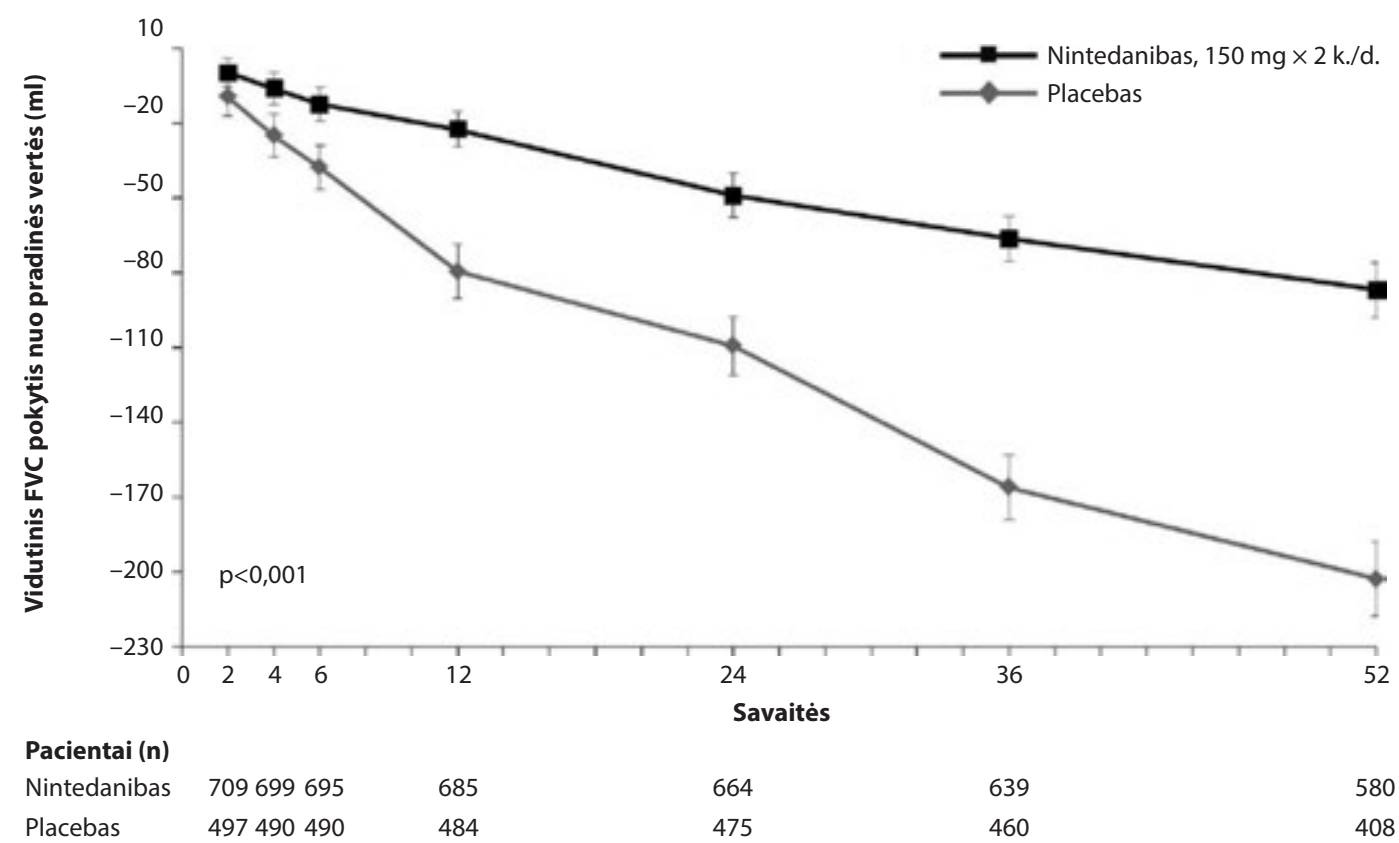

1 pav. Vidutinis FVC pokytis (ml) nuo pradinio lygio INPULSIS ir TOMORROW klinikiniuose tyrimuose

FVC - forsuota gyvybinè plaučių talpa (angl. Forced Vital Capacity)

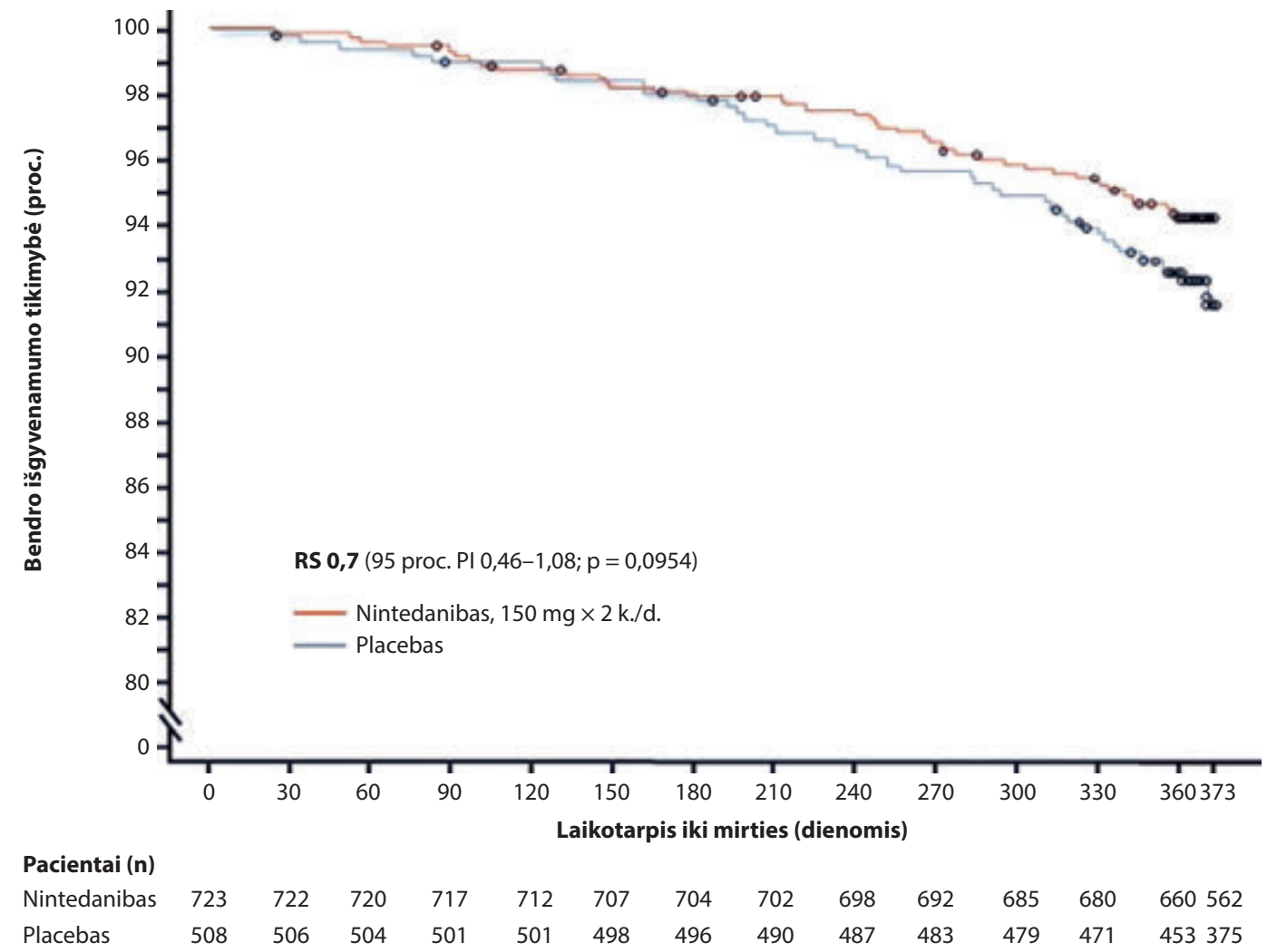

2 pav. Bendrojo išgyvenamumo tikimybė TOMORROW ir INPULSIS klinikiniuose tyrimuose (rezultatai pateikiami procentais, Kaplan-Mejerio kreive, laikotarpis iki mirties per 52 sav.) ( $p=0,0954)$.

PI 0,34-0,97; $\mathrm{p}=0,0274)$. Nors statistiškai nereikšmingi, tačiau panašūs nintedanibo poveikio rezultatai buvo nustatyti bendrajam mirtingumui ( 8,3 proc. - nintedanibo ir 5,8 proc. - placebo grupèse; RS 0,7; PI
0,46-1,08; $\mathrm{p}=0,0954)$ ( 2 pav.) ir mirtingumui, susijusiam su kvejpavimo sistemos ligomis (nintedanibo grupeje $-3,6$ proc. mirusiųu, placebo $-5,7$ proc.; RS $0,62 ; 95$ proc. PI $0,37-1,06 ; \mathrm{p}=0,0779)$. 


\section{Farmakoterapija}

Kitas svarbus rodiklis, susijęs su mirtingumu, yra plaučių funkcijos prastėjimas. FVC sumažèjimas daugiau nei 10 proc. būtinojo dydžio per 6 mèn. siejamas su padidejusia mirštamumo rizika ( $\mathrm{RS} 2,8 ; 95$ proc. PI 1,5-5,06; $\mathrm{p}<0,001)$. INPULSIS tyrimas taip pat apskaičiavo FVC kitimą per 52 savaičių laikotarpí. Lyginant su placebo grupe, nintedanibo grupeje didesniam skaičiui pacientų FVC nekito (30 proc. - nintedanibo grupeje ir 15 proc. - placebo grupeje; šansų santykis (ŠS) 2,5; 95 proc. PI 1,9 - 3,5; $\mathrm{p}<0,001$ ).

Apibendrinus galima teigti, kad nintedanibas mažina FVC kritimą ir paūmèjimų dažnị, taip lètindamas ligos progresavimą bei mažindamas IPF sergančių pacientų mirštamumą.

\section{NINTEDANIBO SAUGUMAS}

Nintedanibas yra gerai toleruojamas daugelio pacientų, o dažniausi nepageidaujami reiškiniai yra lengvi arba vidutinio sunkumo. Dažniausia nepageidaujama nintedanibo reakcija yra viduriavimas. Duomenys iš TOMORROW ir INPULSIS tyrimų parodè, kad 61,5 proc. pacientų, vartojusių nintedanibą, viduriavo, o placebo grupejje viduriavimas užfiksuotas 17,9 proc. atvejų. Dèl nepageidaujamų reiškinių gydymas nintedanibu buvo laikinai sustabdytas 20,6 proc. pacientų (dèl viduriavimo - 5,3 proc. atvejų), o placebo grupeje - 15 proc. atvejų.

Kiti nepageidaujami reiškiniai yra kraujavimas ir kepenų fermentų padidejimas. Nintedanibas slopina kraujagyslių endotelio augimo veiksnio receptorius, todèl gali didinti kraujavimo riziką. INPULSIS tyrimuose kraujavimo epizodai nintedanibo grupeje nustatyti 10 proc. atveju, placebo -7 proc. atvejų. 14 proc. pacientų, gydomų nintedanibu, buvo nustatytas kepenų fermentų kiekio padidejimas, tuo tarpu placebo grupejje - tik 3 proc. pacientų. Laikinai gydymą nutraukus arba sumažinus vaisto dozę, kepenų fermentų kiekis normalizuojasi, tačiau rekomenduojama ištirti kepenų funkciją prieš skiriant gydymą, o po to periodiškai tikrinti ir gydymo metu.

INPULSIS-ON tyrimų duomenys taip pat patvirtina nintedanibo saugumą ir toleravimą. Viduriavimu skundèsi mažiau INPULSIS-ON tyrimo pacientų $(62,5$ atvejo 100 pacientų per metus, tęsiančių nintedanibą, ir 73,7 atvejo 100 pacientų per metus, pradejusių vartoti nintedanibą) nei pacientai INPULSIS tyrimuose (112,6 atvejų 100 pacientų per metus). Gydymo nutraukimo dažnis dèl viduriavimo INPULSIS-ON tyrime (atitinkamai 4,4 ir 10, 5 atvejo 100 pacientų per metus tęsiančių ir naujai pradejjusių vartoti nintedanibą) buvo toks pats kaip ir INPULSIS tyrimuose (4,4 atvejo 100 pacientų per metus). Šie duomenys iš INPULSIS-ON tyrimo, trukusio 63 mèn., patvirtina gydymo nintedanibu saugumą ir toleravimą.

Nintedanibo saugumas ir toleravimas buvo įvertinti ir realioje klinikineje praktikoje. Nepageidaujamų reiškinių dažnis atitinka klinikinių tyrimų duomenis: viduriavimas buvo dažniausiai pasireiškiantis nepageidaujamas reiškinys tyrime JAV (63 proc. vartojusių nintedanibą), ị kurị buvo ịtraukti 6758 pacientai, gydyti nintedanibu (duomenys per vienerių metų laikotarpi po vaisto patekimo i̇ rinką). Vidutiné nintedanibo vartojimo trukmé - 113 dienų (vartojimo intervalas 6-390 dienų). Iš 4062 nepageidaujamų reiškinių, 322 atvejai buvo mirtini (iš jų 27 mirtys siejamos su širdies ir kraujagyslių sistemos ligų komplikacijoms, 8 atvejai nuo miokardo infarkto, 3 atvejai - nuo insulto ir 2 - nuo nukraujavimo).

\section{IŠVADOS}

Klinikinių tyrimų analizės parodè, kad nintedanibas veiksmingas tarp skirtingų IPF sergančių pacientų, nepriklausomai nuo jų amžiaus, lyties ir plaučių funkcijos. Nintedanibas yra veiksmingas pacientams ir ligos pradžioje, ir esant pažengusiai ligai, nes lètina IPF progresavimą ir mažina paūmèjimų dažnị. Gydymas nintedanibu yra saugus. Dažniausiai pasireiškianti nepageidaujama reakcija - viduriavimas, dèl kurio gydymas nintedanibu laikinai nutraukiamas arba sumažinama jo dozė tik mažai daliai pacientų. Realios klinikinès praktikos duomenys sutampa su klinikinių tyrimų duomenimis, tad nintedanibas yra veiksmingas, gerai toleruojamas ir saugus gydyti pacientus, sergančius IPF.

LT/OFE/0418/00020

\section{LITERATŪRA}

1. Rodriguez-Portal JA. Efficacy and safety of nintedanib for the treatment of idiopathic pulmonary fibrosis: an update. Drugs R D. 2018; 18(1):19-25.

2. Richeldi L, Bois RM, Raghu G, Azuma A, Brown KK, Costabel U, et al. Efficacy and safety of nintedanib in idiopathic pulmonary fibrosis. N Engl J Med. 2014; 370(22):2071-82.

3. Richeldi L, Kreuter M, Selman M, Crestani B, Kirsten AM, Wuyts WA, et al. Long-term treatment of patients with idiopathic pulmonary fibrosis with nintedanib: results from the TOMORROW trial and its open-label extension. Thorax. 2017: pii: thoraxjnl-2016-209701. Available from: http:// thorax.bmj.com/content/thoraxjnl/early/2017/10/09/thoraxjnl-2016-209701.full.pdf

4. Richeldi L, Cottin V, Bois RM, Selman M, Kimura T, Bailes $Z$, et al. Nintedanib in patients with idiopathic pulmonary fibrosis: Combined evidence from the TOMORROW and INPULSIS trials. Respir Med. 2016; 113:74 -9. 